
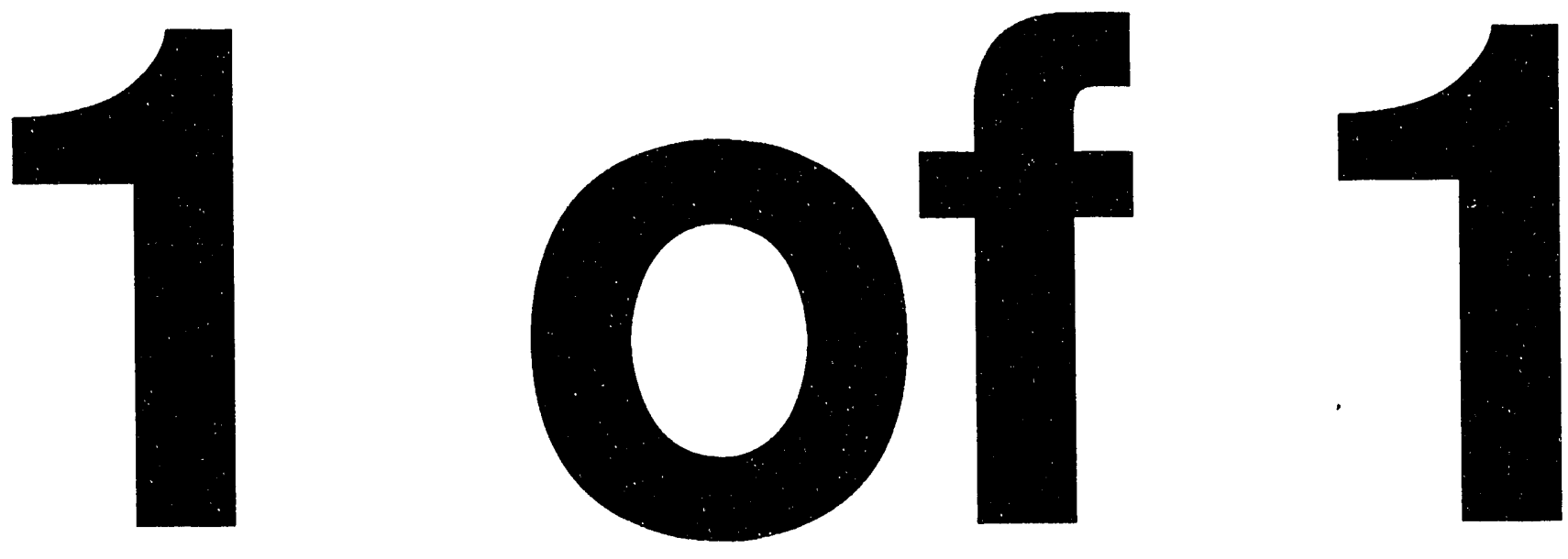
EGG-OTTA-10638

\section{SUMMARY OF SUMMARY OF
TIGER TEAM ASSESSMENT AND TECHNICAL SAFETY APPRAISAL
RECURRING CONCERNS IN THE MAINTENANCE AREA}

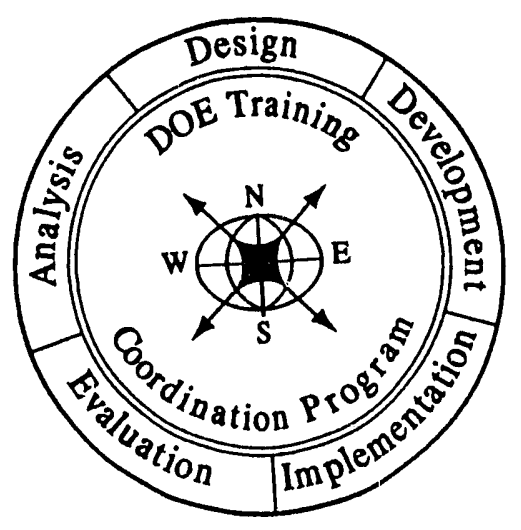

Published January 1993

DOE Training Coordination Program Idaho National Engineering Laboratory EG\&G Idaho, Inc. Idaho Falls, Idaho 83415

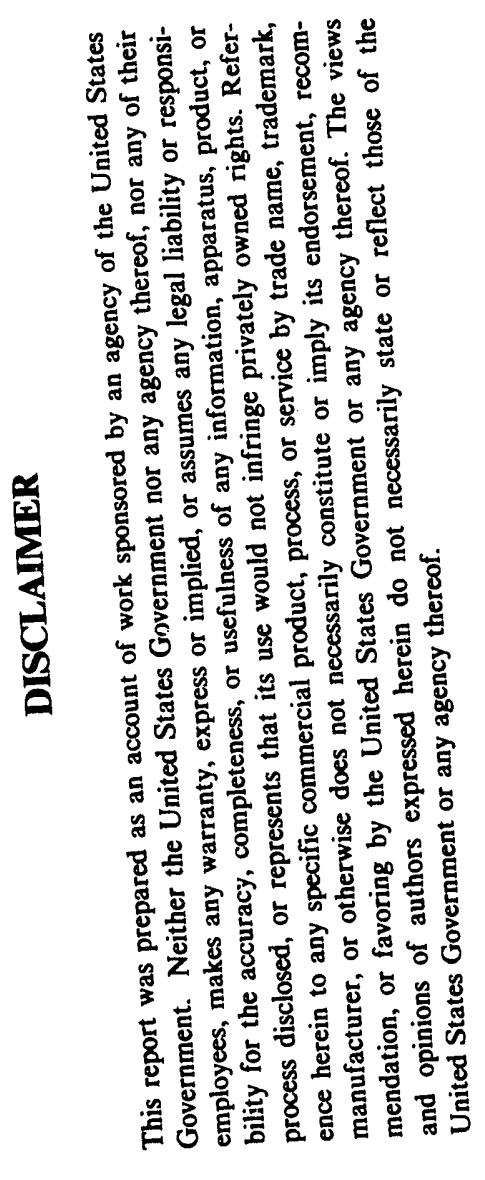

Prepared for the

U.S. Department of Energy

Office of Nuclear Energy

Office of Nuclear Safety Policy and Standards

Under DOE Field Office, Idaho

Contract DE-AC07-76IDO1570

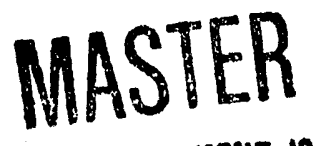




\section{FOREWORD}

The purpose of the Summary of Tiger Team Assessment and Technical Safety Appraisal Recurring Concerns in Maintenance is to provide DOE contractor organizations with information that can be used in evaluating their maintenance programs against identified concerns and noteworthy practices. This document can be a valuable tool in identifying and correcting maintenance program weaknesses. 
Intentionally Blank 


\section{CONTENTS}

FOREWORD $\ldots \ldots \ldots \ldots \ldots \ldots \ldots \ldots \ldots \ldots \ldots \ldots \ldots \ldots \ldots \ldots$

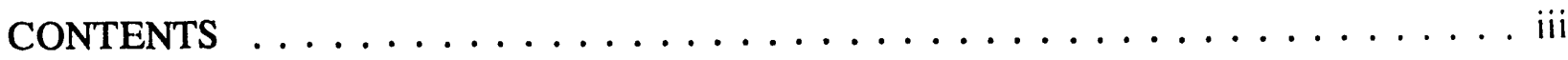

INTRODUCTION $\ldots \ldots \ldots \ldots \ldots \ldots \ldots \ldots \ldots \ldots \ldots \ldots \ldots \ldots$

RECURRING CONCERNS $\ldots \ldots \ldots \ldots \ldots \ldots \ldots \ldots \ldots \ldots \ldots$

NOTEWORTHY PRACTICES $\ldots \ldots \ldots \ldots \ldots \ldots \ldots \ldots$

OTHER IDENTIFIED CONCERNS $\ldots \ldots \ldots \ldots \ldots \ldots \ldots \ldots \ldots \ldots$

MA. 1 ORGANIZATION AND ADMINISTRATION $\ldots \ldots \ldots \ldots \ldots \ldots$

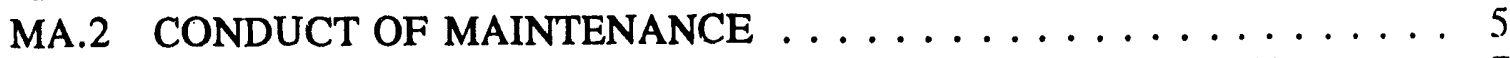

MA.3 MAINTENANCE FACILITIES, EQUIPMENT, AND MATERIAL . . . . 7

MA.4 PLANNING, SCHEDULING, AND WORK CONTROL . . . . . . . . 8

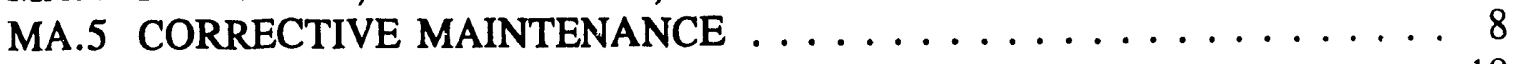

MA.6 PREVENTIVE MAINTENANCE $\ldots \ldots \ldots \ldots \ldots \ldots \ldots \ldots$

MA.7 PREDICTIVE MAINTENANCE $\ldots \ldots \ldots \ldots \ldots \ldots \ldots \ldots$

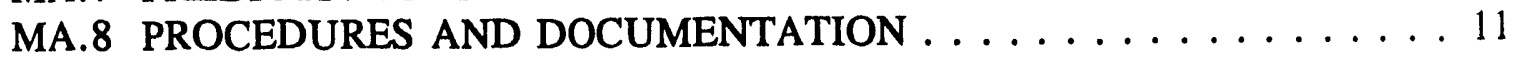


Intentionally Blank 


\section{SUMMARY OF \\ TIGER TEAM ASSESSMIENT AND TECHNICAL SAFETY APPRAISAL RECURRING CONCERNS IN THE MAINTENANCE AREA}

\section{INTRODUCTION}

Fourteen Tiger Team Assessment and eight Technical Safety Appraisal (TSA) final reports have been received and reviewed by the DOE Training Coordination Program during Fiscal Year 1992. These assessments and appraisals included both reactor and non-reactor nuclear facilities in their reports. The Tiger Team Assessments and TSA reports both used TSA performance objectives, and list "concerns" as a result of their findings. However, the TSA reports categorized concerns into the following functional areas: 1) Organization and Administration, 2) Radiation Protection, 3) Nuclear Criticality Safety, 4) Occupational Safety, 5) Engineering/Technical Support, 6) Emergency Preparedness, 7) Safety Assessments, 8) Quality Verification, 9) Fire Protection, 10) Environmental Protection, and 11) Energetic Materials Safety. Although these functional areas match most of the TSA performance objectives, not all of the TSA performance objectives are addressed. For example, the TSA reports did not include Training, Maintenance, and Operations as functional areas. Rather, they included concerns that related to these topics throughout the 11 functional areas identified above. For consistency, the Maintenance concerns that were identified in each of the TSA report functional areas have been included in this summary with the corresponding TSA performance objective.

The Tiger Team Assessments and TSAs were reviewed and evaluated for concerns in the Maintenance Area (MA). Two hundred and thirty one (231) maintenance concerns were identified by the Tiger Team Assessments and TSA reports. These recurring concerns appear below. A summary of the Noteworthy Practices that were identified and a compilation of the maintenance concerns for each performance objective that were not considered as recurring are also included. Where the Tiger Team Assessment and TSA identified the operating contractor or facility by name, the concern has been modified to remove the name while retaining the intent of the comment. 


\section{RECURRING CONCERNS}

The following concerns are considered to be recurring (two or more facilities) and are categorized under their appropriate performance objective heading in order of decreasing frequency of observation.

\section{MA.1 Organization and Administration}

1. Maintenance Management Plans are either non-existent or are not in full compliance with DOE requirements (11).

2. Organizational structure and the related responsibilities, authorities, and procedural methods are not defined (8).

3. Corrective, preventive, and predictive maintenance programs do not presently exist or are not effective (2).

4. The operating contractor has not applied a graded approach to maintenance activities (2).

5. The operating contractor has not established goals and objectives or performance indicators for maintenance (2).

6. Management supervision of worker performance and review of administrative practices at facilities does not ensure effective implementation and control of maintenance activities (2).

\section{MA.2 Conduct of Maintenance}

1. Maintenance activities are not reviewed or controlled (4).

2. Maintenance practices do not ensure that maintenance areas are kept in an orderly, clean, and safe condition (2).

3. Facility and industry experiences are not distributed in a lessons-learned program (2).

\section{MA.3 Maintenance Facilities, Equipment, and Material}

1. Systems are not in place that ensure all instruments, measuring, and test equipment requiring calibration have been identified and their calibration maintained (8).

2. Material supply and storage control is not conducted in an effective manner (7). 
3. Lifting, hoisting, and rigging equipment is not inspected (5).

4. Maintenance equipment is not maintained in a safe and operable condition (3).

5. Maintenance facilities and equipment are insufficient to perform maintenance in a safe and efficient fashion (2).

MA.4 Planning, Scheduling, and Work Control

1. The planning, scheduling, and work control system does not ensure that maintenance activities are conducted in a timely and efficient manner (9).

2. Safe operation of the facility is compromised by the large and increasing maintenance repair backlog (4).

MA.5 Corrective Maintenance

1. A corrective maintenance program has not been implemented which ensures that equipment is maintained to uniform, high standards (7).

MA.6 Preventive Maintenance

1. Preventive maintenance programs are not fully in place (12).

MA.7 Predictive Maintenance

1. Predictive maintenance programs are not fully in place (6).

2. Equipment history and predictive maintenance analysis are not used to optimize equipment performance (6).

MA.8 Procedures and Documentation

1. Formal maintenance procedures are either nonexistent, incomplete, or not used (10).

2. Provisions for personnel protection during maintenance are not addressed in operating contractor procedures (5).

3. Maintenance records are not prepared and controlled in accordance with DOE Orders or operating contractor procedures (5). 


\section{NO'TEWORTHY PRACTICES}

There were no noteworthy practices identified by the Tiger Team Assessments or Technical Safety Appraisals in the maintenance area.

\section{OTHER IDENTIFIED CONCERNS}

The following are maintenance concerns from the Tiger Team Assessments and Technical Safety Appraisals that were not considered recurring. In instances where the concern referenced the facility, the words have been modified to remove the reference yet retain the intent of the concern.

\section{MA.1 ORGANIZATION AND ADMINISTRATION}

Performance Objective: Maintenance organization and administration should ensure effective implementation and control of maintenance activities.

o The operating contractor has not established technical standards for the performance of maintenance.

o A uniform work control procedure governing maintenance activities has not been implemented.

o Real property and facility equipment is not maintained in accordance with DOE requirements.

o The operating contractor has permitted hazardous conditions to exist during continued operations because of a backlog of electrical parts.

o The preventive and predictive maintenance programs have not been reviewed by the DOE Field Office.

o The operating contractor's concerns regarding the work control and planning portion of the DOE Field Office draft implementation guidance have not been addressed.

- Short safety messages on maintenance repair orders as a reminder of any potential danger on the job (e.g., Asbestos Caution, Caution High Temperatures) have not been implemented as an interim measure until the computerized maintenance system is functioning.

o A system does not exist which identifies (with supporting drawings, manuals, and warranties) all real property that requires maintenance. 
o Program equipment is being installed without the notification of plant engineering.

o Resources have not been allocated to enable the implementation of DOE requirements in a timely manner.

- The lack of a formal configuration control program results in inefficiencies and, in some cases, potentially hazardous maintenance conditions.

o Many maintenance-worthy items are not currently being maintained.

o Detailed planning of maintenance activities is not proceeding in an orderly fashion and a schedule for addressing this deficiency has not been developed by the DOE Field Office.

o The maintenance program conducted on active and inactive facilities has not been effective in preventing the deterioration of these facilities.

o The current dual responsibilities of operators for maintenance as well as operation have resulted in plant maintenance items being deferred or neglected.

o Management of maintenance work is not being done in a timely manner.

o The operating contractor's inspection and supervision of maintenance operations do not adequately prevent dangerous conditions at worksites.

o Electrical and mechanical trades personnel expressed concerns over the safety and availability of trucks used to haul heavy loads. The operating contractor has not investigated this concern and documented findings and any corrective actions.

o Maintenance and engineering functions do not enable line managers to control and improve support services.

\section{MA.2 CONDUCT OF MAINTENANCE}

Performance Objective: Maintenance should be conducted in a safe and effective manner to support each facility condition and operation on the site.

o The operating contractor has not implemented controls in preventive maintenance programs which minimize exposure of personnel to significant hazards during the performance of work.

- Certification of satisfactory completion of maintenance work and traceability of the certifier is not included in many corrective and preventive maintenance procedures. 
o Lockouts/tagouts are not being performed in a manner which ensures the safety of individuals conducting work.

o The operating contractor has not established a program to increase maintenance effectiveness through the identification, documentation, and analysis of rework.

o An effective system is not in place to ensure that maintenance personnel check with the proper authorities before undertaking work.

o Operational Safety Requirements are not incorporated into maintenance documentation.

o The operating contractor has not developed and implemented a plan which assures that maintenance is performed in a safe and efficient manner.

o The maintenance program does not meet systematic documentation requirements.

o Use of outdated drawings, lack of written procedures, and lax enforcement of informal procedures has resulted in unsafe practices.

o Maintenance managers and supervisors do not take an active role in minimizing the exposure of personnel to hazardous conditions.

o There is a lack of emphasis on training and qualification of electrical craftspersons and mechanical supervisors supervising electrical crafts.

o The Electrical Safe Work Practices Manual does not include appropriate National Standards requirements.

o The electrical work practice program has not been fully implemented.

- Because of procedural and certification deficiencies, there is insufficient assurance that maintenance work is conducted properly.

o Generic maintenance problems are not being regularly identified and tracked.

o In most cases, the conduct of maintenance on test equipment does not address deficiencies in a controlled fashion and does not effectively minimize deterioration of this equipment.

o Written and approved maintenance procedures are not always used for the conduct of maintenance tasks. 
- The maintenance training programs and training records for operators working on program equipment do not meet DOE requirements.

o Procedures designed to achieve as-low-as-reasonably-achievable radiation exposures for maintenance workers are not being followed.

- Welders who have not been trained and certified are performing work on programmatic equipment.

o Requirements for formal certification of satisfactory completion of work for maintenance activities do not comply with DOE requirements.

- Most maintenance supervisory personnel are not formally certified to direct maintenance work activities.

\section{MA.3 MAINTENANCE FACILITIES, EQUIPMENT, AND MATERIAL}

Performance Objective: Facilities, equipment, and material should effectively support the performance of maintenance activities.

o A site freeze protection program has not been developed and implemented.

- Maintenance management is not controlling facility work areas in accordance with generally accepted industrial practices to ensure the safety of personriel.

o Personnel safety equipment postings and procedure requirements are not being adhered to by maintenance personnel.

o In some work areas, maintenance management is not ensuri..g housekeeping is maintained.

- The operating contractor has not provided personal protective equipment for all maintenance activities.

- A plan to dispose of defective bolts, which includes provisions to ensure that such deficient materials does not re-enter the commercial stream, has not been formulated.

- Personnel safety may be jeopardized by the inadvertent use of low-strength bolts in applications where high-strength bolts are required.

o Use of improper equipment, improperly installed equipment, and untested/uncertified equipment places personnel at high risk of injury. 
o The operating contractor does not have a program to ensure that appropriate safety devices are periodically inspected.

\section{MA.4 PLANNING, SCHEDULING, AND WORK CONTROL}

Performance Objective: The planning, scheduling, and control of work should ensure that identified maintenance actions are properly completed in a safe, timely, and effective manner.

o Personnel have not been instructed on proper inspection and post-maintenance control procedures.

o Some safety-related maintenance tasks are not entered into the work control system and are not always addressed in a timely manner.

o Work orders do not receive the level of independent review consistent with their safety or technical importance.

o Current staffing levels may not be sufficient to handle the added work load resulting from the increased attention to safety and health.

o Maintenance and modification activities having potential safety concerns have been conducted by unauthorized personnel outside of the operating contractor work order control system.

o Work packages do not contain sufficient scope and detail to ensure that maintenance activities are conducted and verified effectively.

o Facility maintenance activities are currently being conducted without guidance or input from DOE with respect to current and long-range planning.

o Management is not provided information to plan, schedule, and control maintenance.

\section{MA.5 CORRECTIVE MAINTENANCE}

Performance Objective: The material condition of components and equipment should be maintained to support safe and effective operation of all facilities on the site.

o Management has not established a method to mark deficiencies in the workplace to indicate they have been identified and entered into the work control system. 
- Seismic analysis has not been performed to determine the need to tie down heavy items.

- The status of transformers is not well documented and potential hazardous conditions may exist.

- Engineering and safety assistance provided to the maintenance organization has not been sufficient.

o The maintenance organization has not maintained the material condition of components and equipment in a manner to prevent hazardous conditions caused by non-code installations, improper operation of equipment, and equipment deterioration.

o A proactive method of incorporating maintenance worker comments into corrective maintenance activities and trend analysis has not been instituted.

o Corrective maintenance by the operating contractor is substandard and is not responsive to outstanding work orders.

o Corrective maintenance performed is not consistent with operating contractor standards.

o Controls to identify, track, and correct material deficiencies do not comply with DOE requirements.

o Periodic inspection and corrective maintenance of inactive facilities does not preclude the existence of hazardous conditions which contributes to the deterioration of these facilities.

- Material deficiencies exist that are not being corrected.

o The maintenance inspection program established to identify and ensure good condition of components and equipment is not effective.

- Management of resources has not been sufficient to inspect and maintain facilities in a safe condition.

o Hazards associated with hydrogen sulfide production and generation have not been completely identified and controlled.

- The operating contractor has not taken actions to preclude sites from becoming hazardous due to lack of maintenance to surface and subsurface equipment. 
o Maintenance managers have not implemented a formal program to assess facility area conditions.

o There is no program to ensure that equipment, structures, and systems that are inactive, but are not in the decontamination and decommissioning program, are maintained in such a way that they will not pose a hazard to personnel or a threat to public health and safety.

o Responsibilities of building managers are not clearly defined.

o The condition of equipment, identification of problems, and correction of deficiencies related to safety, material condition, and housekeeping are not in compliance with DOE requirements.

o Equipment is not maintained in a reliable condition to support facility operations.

\section{MA.6 PREVENTIVE MAINTENANCE}

Performance Objective: Preventive maintenance should contribute to optimum performance and reliability of systems and equipment important to operations.

o Management has not established a policy which ensures preventive maintenance for equipment that is past due receives elevated scheduling priority.

Acceptance criteria and appropriate action statements (for not meeting criteria) are not incorporated into all preventive maintenance procedures.

All appropriate equipment should be included in the preventive maintenance program.

o The operating contractor does not have a preventive maintenance program for cranes and hoists which identifies and corrects deficiencies in a timely manner.

In most cases, preventive maintenance procedures employed by the maintenance organization lack sufficient detail to assure all steps are performed as required.

o Maintenance activities are deficient with regard to in-service inspections and the assessment and tracking of age-related degradation.

- Preventive maintenance procedures do not, in some instances, demonstrate the operability of the equipment being tested.

In some instances, maintenance personnel do not follow lockout procedures. 
- Documented preventive maintenance procedures (including equipment lists, checklists, and schedules) are not used to assure that equipment is maintained in proper operating condition.

- Facilities have not been maintained at most field sites to protect equipment from the environment to minimize downtime and maintenance.

o The schedules for electrical equipment and lubrication preventive maintenance programs are not being followed.

o The operating contractor has not implemented a configuration control program.

o One major piece of emergency equipment is not included on the preventive maintenance list.

\section{MA. 7 PREDICTIVE MAINTENANCE}

Performance Objective: Maintenance history evaluation and systematic root cause analyses should be used to support maintenance activities and optimize equipment performance.

o Predictive maintenance is not used to develop and refine maintenance procedures.

\section{MA.8 PROCEDURES AND DOCUMENTATION}

Performance Objective: Maintenance procedures and related documents should provide appropriate directions and guidance for work, and should be used to ensure that maintenance is performed safely and effectively.

- The operating contractor does not have current as-built drawings to support maintenance activities.

o Revisions to maintenance documents are not properly controlled.

- Maintenance work control procedures are not always effectively reviewed for conditions which could affect safety and for proper definitions of the practices to be used.

- Maintenance procedures do not comply with both DOE requirements and operating contractor procedures. 
o The procedure for maintenance request uses the terms "minor repairs and/or maintenance" which could cause the degradation of systems or the potential for unreviewed safety questions.

o Detailed drawings of all critical safety systems within facilities have not been reviewed to ensure that they are available and current.

o Maintenance procedures do not provide accurate and complete detailed information to enable users to understand and perform their activities safely and efficiently.

o Operating contractor draft procedures do not embody optional paths and criteria which would enable a user to match procedural instructions to the complexity and importance of the work to be performed.

o Maintenance control procedures are deficient regarding such matters as requiring work to be done in accordance with current procedures, establishing hold points for quality verification, and developing inspection requirements and procedures.

o The operating contractor does not have complete and correct procedures in place in all cases during conduct of maintenance.

o Maintenance procedures have not been adequately corrected and updated.

o The practice of updating the master set of engineering prints before a modification is actually installed is inappropriate.

o The operating contractor work control system is inadequate.

o Operation and maintenance procedures must be written for equipment under the responsibility of plant maintenance. 

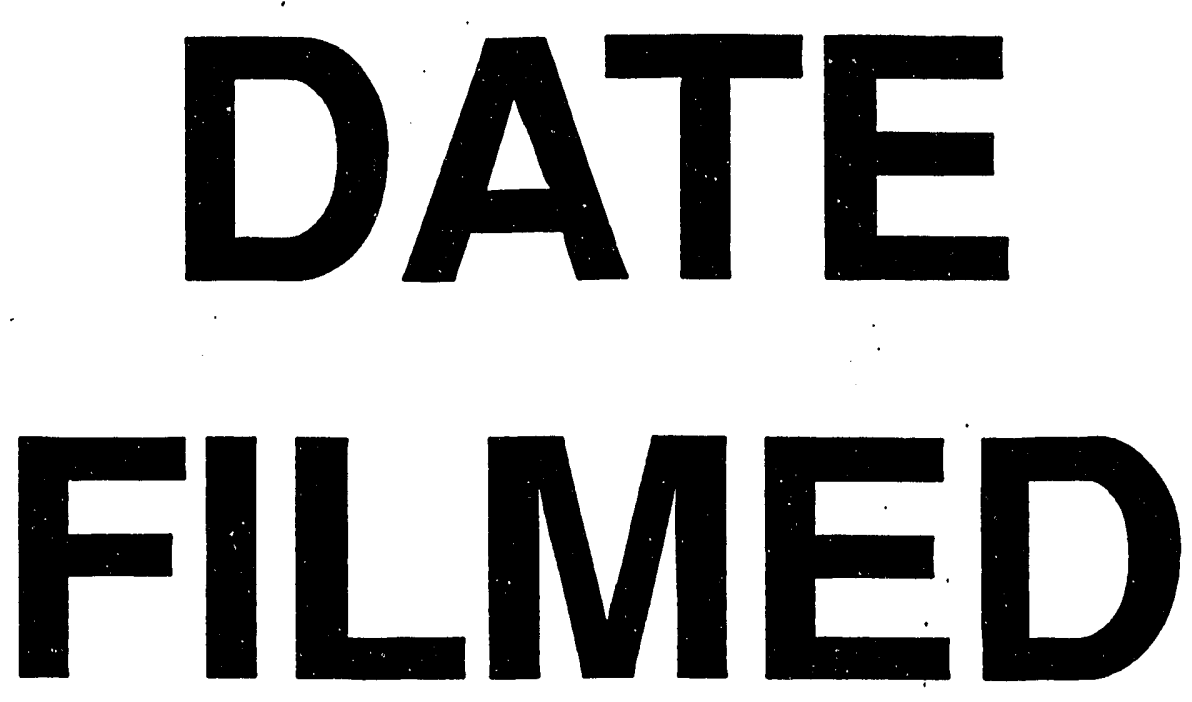

$9 / 10 / 93$
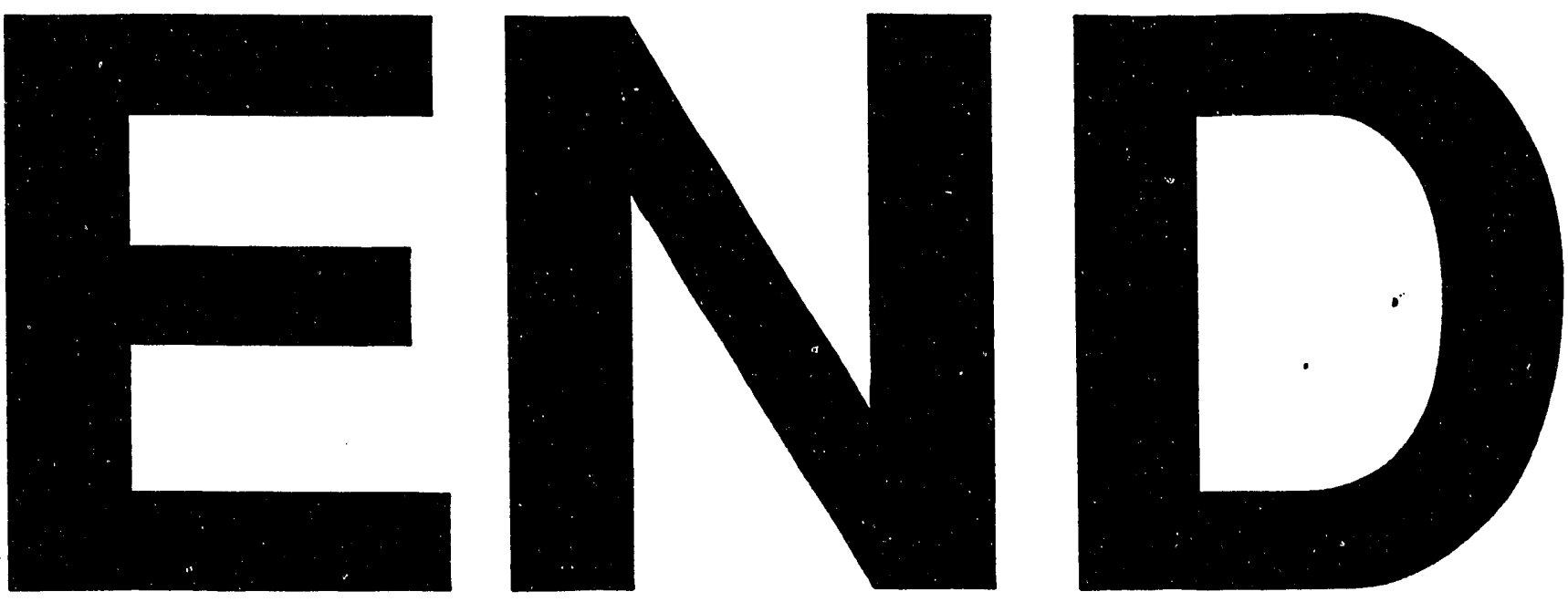
